\title{
Risedronate once monthly: a potential new regimen for the treatment of postmenopausal osteoporosis
}

\author{
María J Moro-Álvarez' \\ Manuel Díaz-Curiel ${ }^{2}$ \\ 'Hospital Central Cruz Roja, Madrid, \\ ${ }^{2}$ Fundación Jiménez Díaz, Madrid, \\ Spain, Internal Medicine, Metabolic \\ Bone Disease Unit
}

\begin{abstract}
Postmenopausal osteoporosis increases susceptibility to low-trauma fractures due to reduced bone volume and microarchitectural deterioration. Daily nitrogen-containing bisphosphonates have shown antifracture efficacy in many studies and are the most commonly prescribed treatment for women with postmenopausal osteoporosis. However, optimal efficacy is often not achieved due to poor patient adherence to medication. Current dosing schedules are often inconvenient or impractical for patients. Poor adherence increases risk of fracture, which itself increases morbidity, healthcare costs and, potentially, mortality. Although weekly rather than daily dosing of bisphosphonates has improved adherence, significant problems remain. Efforts to reduce dosing frequency as a possible means for further improving adherence (compliance and persistence), and therefore treatment outcomes, are ongoing. Risedronate, a third-generation bisphosphonate, has been shown in multiple clinical trials to reduce fracture risk and improve bone mineral density in postmenopausal women with osteoporosis. Risedronate has a specific structure and set of characteristics that enable less frequent dosing. This paper reviews the structure of risedronate, and how this translates into high antiresorptive potency, favorable bone binding, persistence in bone, and good tolerability that permits less frequent dosing. The paper also reviews the clinical evidence for risedronate, demonstrating the viability of less frequent dosing, with its potential benefits for patient convenience and adherence to therapy. Two equivalence or non-inferiority bridging studies have demonstrated the option of novel risedronate dosing regimens. These studies are reviewed to demonstrate the efficacy and safety of two different monthly regimens of risedronate in the treatment of postmenopausal osteoporosis: $75 \mathrm{mg}$ on 2 consecutive days a month and $150 \mathrm{mg}$ once a month. Data for oral risedronate $150 \mathrm{mg}$ once a month are limited to 1 year's treatment duration. In previous clinical trials, patients receiving risedronate $5 \mathrm{mg}$ daily have been followed for up to 7 years, with no evidence of loss of effectiveness. Risedronate $150 \mathrm{mg}$ once a month has a comparable efficacy and safety to daily doses in the treatment of postmenopausal osteoporosis. These additional treatment options with risedronate provide easier dosing alternatives for patients.
\end{abstract}

Keywords: osteoporosis, bone mineral density, fracture, bisphosphonates, risedronate

\section{Introduction}

Osteoporosis has been defined as a systemic disease characterized by low bone mass and disruption of bone architecture resulting in reduced bone strength and an increased relative risk of fracture. The prevalence of osteoporosis is estimated at over 200 million people worldwide (Reginster and Burlet 2006). In the US and Europe, about $30 \%$ of all postmenopausal women are affected by osteoporosis (Reginster and Burlet 2006). As the population ages worldwide, the number of people with osteoporosis is expected to rise correspondingly. Current annual rates of osteoporotic fractures are estimated at around 1.5 million in the US and 3.8 million in Europe (Reginster and Burlet 2006). In 1990, the incidence of new hip fractures worldwide 


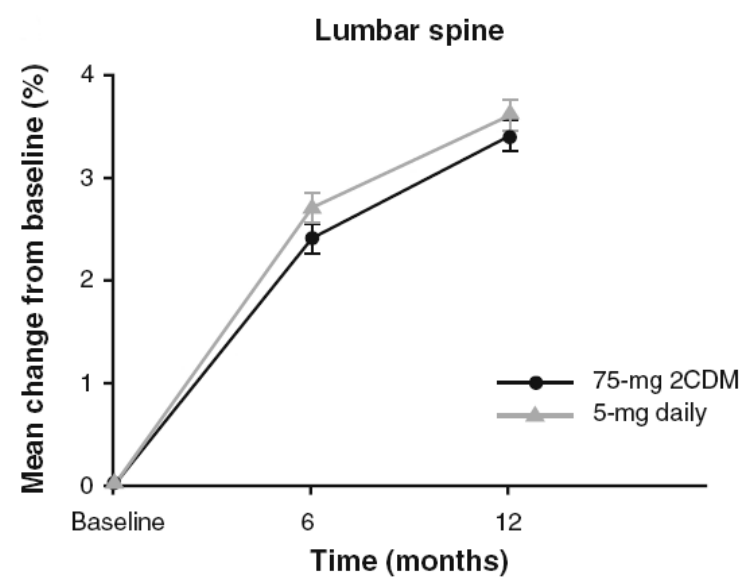

Figure I Mean percentage change from baseline in lumbar spine mineral density. There were no statistically significant differences between treatments groups at any time point. After Delmas et al (2008).

was 1.7 million, but this figure is estimated to increase to 2.6 million by 2025 (Reginster and Burlet 2006). Direct expenditure related to osteoporotic fractures was US\$17 billion in the US in 2001; in the European Union costs were US\$32 billion in 2000 and are expected to double by 2050 (Reginster and Burlet 2006).

\section{Adherence to treatment of osteoporosis}

Treatment to decrease the risk of osteoporotic fractures may include bisphosphonates, raloxifene, teriparatide, estrogen, calcitonin, and strontium ranelate. Despite the proven efficacy of bisphosphonates in reducing both vertebral and non-vertebral fractures, and increasing bone mineral density (BMD), not all patients gain maximum benefit from these therapies. A major reason cited for suboptimal efficacy of oral bisphosphonates is poor longterm adherence to medication therapies, a common feature of chronic disease (WHO 2003). Poor adherence can have serious consequences. Studies have shown that patients who do not adhere to their dosing schedule have insufficiently decreased bone resorption (Eastell et al 2003), lower treatment-related increases in BMD (Finigan et al 2001; Yood et al 2003; Sebalt et al 2004), and, most importantly, a significantly increased risk of fracture (Caro et al 2004; McCombs et al 2004; Sebalt et al 2004).

Fractures resulting from poor adherence increase direct and indirect medical costs, and mortality (Chrischilles et al 1991; Caro et al 2004; McCombs et al 2004). Both patient and medication factors are involved in this major problem, one being the complexity of the dosing regimen (Cramer et al 2007; Lekkerkerker et al 2007) or a complex dosing schedule of therapy (Mersfelder et al 1999; Lombas et al 2001; Segal et al 2003).

Due to poor adherence to anti-osteoporotic treatments, maximizing compliance should be a primary focus of clinical management (NAMS 2006). Newer formulations of bisphosphonates have been developed. Dosing frequency influences compliance. Currently alendronate is available as a daily or weekly therapy and ibandronate is available as a monthly therapy. Risedronate in a daily, weekly, or a twice-monthly dosing regimen $(75 \mathrm{mg}$ on 2 consecutive days each month) was recently approved by the US Food and Drug Administration (FDA) (Brown et al 2002; Emkey 2004; Delmas et al 2004, 2008; Miller et al 2005).

Patients prefer these new dosing formulations (Simon et al 2002; Baroutsou et al 2004; Kendler et al 2004) and consequently weekly dosing is associated with better persistence (Cramer et al 2004; Ettinger et al 2004) and compliance (Cramer et al 2004; Ettinger et al 2004; Recker et al 2004) than daily dosing. Proven treatment efficacy, however, is another important factor that affects patient preference (Gold et al 2006; Keen et al 2006; Weiss et al 2006). However, adherence rates with weekly regimens are still inadequate. Only 37\%-58\% of patients who received weekly bisphosphonate therapy remained persistent at 1 year, and just $46 \%-69 \%$ complied correctly (Cramer et al 2004; Ettinger et al 2004; Recker et al 2004). These data suggest a need for simpler and less frequent dosing.

A monthly therapy with vertebral, non-vertebral, and hip fracture reduction efficacy would give physicians another treatment option. At the time of this study ibandronate $150 \mathrm{mg}$ is the only bisphosphonate approved for once-monthly administration. The treatment with monthly oral ibandronate produced significant and progressive increases in lumbar spine (LS) BMD of $4.9 \%$ after 1 year in the MOBILE study. Furthermore $150 \mathrm{mg}$ monthly regimen produced similar and significant increases in hip BMD (total hip, femoral neck, and trochanter). Therefore, in women with postmenopausal osteoporosis, monthly ibandronate is at least as effective for BMD endpoints as daily ibandronate (Miller et al 2005). In a previous study daily ibandronate demonstrated a significant reduction of risk of new morphometric vertebral fractures by $50 \%(\mathrm{p}=0.0006)$ versus placebo and a statistically significant relative risk reduction in clinical vertebral fractures of $48 \%$ was observed, but the incidence of non-vertebral fractures was not significantly reduced. However, findings from a posthoc analysis showed that the daily regimen reduces the risk of nonvertebral fractures $(69 \% ; \mathrm{p}=0.012)$ in a higher-risk subgroup (femoral neck BMD T score <3.0) (Chesnut et al 2004). 
FDA and European Medicines Agency (EMEA) guidelines have determined that alternative dosage forms can be approved based upon BMD.

\section{Characteristics of risedronate}

Risedronate is a pyridinil bisphosphonate that has been shown in prospective fracture studies to reduce vertebral and non-vertebral fracture risk (Harris et al 1999; Reginster et al 2000; McLung et al 2001). Several studies have shown that in patients with postmenopausal osteoporosis, risedronate increases BMD by $5.4 \%-5.9 \%$ in the LS and by $1.6 \%-3.1 \%$ in the femoral neck, and reduces vertebral fractures by $41 \%-49 \%$ and hip fractures by 40\% (Harris et al 1999; Reginster et al 2000; McClung et al 2001; Cranney et al 2002).

For an anti-osteoporotic drug to be administered at extended drug-free intervals and provide persistence of effect, it needs to possess certain properties. These properties include high antiresorptive potency, favorable bone binding characteristics, distribution, concentration, and persistence in bone tissue, and good tolerability. Clinical pharmacology and pharmacokinetic studies, and preclinical animal studies have shown risedronate to possess these characteristics. So, like other bisphosphonates, risedronate remains active on the surface of bone for long periods after dosing, providing the opportunity to develop a range of dosing schedules. Although the original dosing regimen for postmenopausal osteoporosis was an oral dose of $5 \mathrm{mg}$ risedronate daily, it was later demonstrated that $35 \mathrm{mg}$ once a week provided similar efficacy and safety to the daily regimen (Brown et al 2002). Risedronate $75 \mathrm{mg}$ each day for 2 consecutive days a month (2CDM) has also been shown to be effective, and was recently approved by the FDA for the treatment and prevention of postmenopausal osteoporosis (Actonel label 2007; McCLung et al 2007; Delmas et al 2008).

\section{Efficacy and safety of monthly dosing of $75 \mathrm{mg}$ risedronate on two consecutive days a month}

This dosing regimen is one of the steps taken towards a once-a-month dosing regimen of $150 \mathrm{mg}$ risedronate. To determine if risedronate $75 \mathrm{mg} 2 \mathrm{CDM}$ regimen is noninferior to risedronate $5 \mathrm{mg}$ daily, 1 year of treatment with risedronate $5 \mathrm{mg}$ daily $(\mathrm{n}=613)$ was compared with risedronate $2 \mathrm{CDM}$ in a international, phase III, randomized, double-blind, parallel-group multicenter study in postmenopausal women with osteoporosis $(n=616)$ (Delmas et al 2007).

The primary efficacy endpoint was the percentage change from baseline in LS BMD at month 12.
Secondary efficacy measures included mean percentage change from baseline in LS and hip BMD, as well as bone turnover markers (BTMs). In addition, the incidence of new vertebral fractures was determined, based on comparison of $\mathrm{X}$-ray measurements from baseline to month 12 .

Non-inferiority in increasing LS BMD was demonstrated with $75 \mathrm{mg} 2 \mathrm{CDM}$ of risedronate, which represents the same cumulative monthly dose of risedronate $(150 \mathrm{mg})$ as the $5 \mathrm{mg}$ daily dosing regimen (treatment difference $0.21: 95 \% \mathrm{CI}$ $0.19-0.62)$. Secondary efficacy analyses similarly showed no clinically relevant differences between the $75 \mathrm{mg} 2 \mathrm{CDM}$ and the $5 \mathrm{mg}$ daily regimens of risedronate: the mean increases from baseline in LS BMD at 1 year were 3.4\% (3.1, 3.7; 95\% CI) vs $3.6 \%(3.3,3.9 ; 95 \% \mathrm{CI})$, respectively. The results were also similar for mean percentage change from baseline in total hip, trochanter, and femoral neck BMD, and BTMs were significant and similar for both treatments groups.

Although the study did not aim to measure fractures, the incidences of vertebral and non-vertebral fractures were similar in the two treatment groups and, for example, new vertebral fractures occurred after 1 year in only $1 \%$ of subjects treated with either risedronate dosing regimen. Treatment efficacy in this study was similar to that in earlier reports with daily or weekly risedronate for both changes in BMD (Reginster et al 2000; Brown et al 2002; Harris 2004) and BTMs (Brown et al 2002; Harris et al 2004).

Safety and tolerability were good for both risedronate dosing regimens, with comparable overall treatment-emergent adverse effects (TEAEs), TEAEs leading to withdrawal, gastrointestinal (GI) tolerability, fractures, and clinical laboratory data. The most commom TEAEs were arthralgia and back pain in both treatment groups. The incidence of TEAEs potentially associated with acute phase reactions was low in both dosing groups and TEAEs were experienced in a higher number of subjects in the group treated with risedronate $75 \mathrm{mg}$ 2CDM (4 subjects) compared with the group taking $5 \mathrm{mg}$ risedronate daily ( 0 subjects). Only $9 \%$ of subjects in either treatment group discontinued treatment prematurely due to an $\mathrm{AE}$, most commonly GI-related.

In conclusion, risedronate $75 \mathrm{mg} 2 \mathrm{CDM}$ was non-inferior and was as well tolerated as $5 \mathrm{mg}$ daily in postmenopausal women with osteoporosis.

\section{Efficacy and safety of risedronate $150 \mathrm{mg}$ once a month}

A recent study has demonstrated comparable efficacy and safety of risedronate $150 \mathrm{mg}$ once-a-month dosing regimen to daily dosing for postmenopausal osteoporosis. 
Two years of treatment with risedronate $5 \mathrm{mg}$ daily $(\mathrm{n}=538)$ was compared with once-a-month risedronate $(\mathrm{n}=556)$ in a international, phase III, randomized, doubleblind, parallel-group multicenter study in postmenopausal women with osteoporosis. The results for the first year of the study have been published, which is continuing for a second year (Delmas et al 2008).

The primary endpoint analysis was a test of non-inferiority comparing the least mean percentage change from baseline in LS BMD in the $150 \mathrm{mg}$ once-a-month and $5 \mathrm{mg}$ daily groups after 12 months. The month 12 measurement or the last postbaseline obtained prior to month 12 was used (last observation carried forward, also referred to as endpoint). This mean percentage change in LS BMD was $3.4 \%$ (95\% CI $3.03 \%-3.82 \%$ ) in the daily group and $3.5 \%$ (95\% CI $3.15 \%-3.93 \%)$ in the once-a-month group (Fig. 1) The difference between groups was $-0.1 \%$ (95\% CI $-0.51 \%-0.27 \%)$. These results indicated that both groups experienced significant improvement from baseline in LS BMD and that the once-a-month regimen was non-inferior to the daily regimen based on prospectively defined criteria. There was no statistically significant difference between the treatment groups in mean percentage change in LS BMD at any time (ie, month 6 , month 12 , or endpoint).

Significant increases from baseline in BMD of sites in the proximal femur (total proximal femur, femoral neck, femoral trochanter) were observed al 6 months and 12 months in both treatment groups. As was the case for LS BMD, there was no statistical difference between treatment groups at any time point at any hip site.

There was no difference between treatment groups in the occurrence of new incident vertebral fracture as determined by morphometric measurement during the first 12 months of treatment.

Significant decreases from baseline in BTMs were observed at 3, 6, and 12 months in both treatment groups and there was no statistically significant difference between treatment groups at endpoint for any of the BTMs.

Both regimens were well tolerated; $9.5 \%$ of patients in the daily group withdrew from treatment as a result of an adverse event and $8.6 \%$ in the once-a-month group. Adverse events of special interest for bisphosphonates (clinical vertebral and non-vertebral fractures, upper GI, and musculoskeletal) were reported by similar proportions of patients in both treatments groups. Incidence of adverse events, adverse events leading to withdrawal, and upper GI adverse events was similar in both treatment groups.
Most events associated with possible acute phase reactions were determined by the investigator to be mild or moderate in severity; only 1 patient, in the once-a-month group, experienced a severe event. The incidence of symptoms potentially associated with an acute phase reaction, although low in both groups, was slightly higher in the monthly group $(1.4 \%)$ than in the daily group $(0.2 \%)$ (Table 1$)$.

Atrial fibrillation was reported by 3 patients $(0.5 \%)$ in the $5 \mathrm{mg}$ daily group and 4 patients $(0.6 \%)$ in the $150 \mathrm{mg}$ once-a-month group. There were no reported cases of osteonecrosis of the jaw.

In conclusion, risedronate $150 \mathrm{mg}$ once a month is similar in efficacy and safety to daily dosing and may provide an alternative for patients who prefer once-a-month oral dosing.

\section{Conclusion}

There is growing evidence to show that complex dosing regimens contribute towards suboptimal adherence to bisphosphonates in women with postmenopausal osteoporosis. Several medications have been shown to decrease fracture rates in clinical trials. However, in real life settings, long-term persistence and compliance to anti-osteoporosis medication is poor, hence decreasing the clinical benefits for patients. Dosing frequency influences compliance; although patients using weekly biphosphonate medication follow their prescribed dosing regimens better than those using daily therapy, overall compliance and persistence rates are suboptimal. Currently risedronate and alendronate are available as a weekly therapy and ibandronate is available as a monthly therapy.

Risedronate is an oral, nitrogen-containing bisphosphonate that possesses properties that provide easier dosing alternatives for patients, such as strong affinity for bone, potent antiresorptive action, high concentration and persistence in bone tissue, and excellent tolerability. The results of recent clinical trials confirm the viability of less frequent dosing with risedronate, and show these regimens to be well tolerated and effective in the treatment of postmenopausal osteoporosis. The study with risedronate $75 \mathrm{mg} 2 \mathrm{CDM}$ was one of the steps taken towards a oncea-month dosing of $150 \mathrm{mg}$ risedronate. The $75 \mathrm{mg} 2 \mathrm{CDM}$ regimen has already been approved by the FDA for the treatment and prevention of postmenopausal osteoporosis.

Risedronate $150 \mathrm{mg}$ once a month is comparable in safety and efficacy to daily dosing in the treatment of postmenopausal osteoporosis. Risedronate $150 \mathrm{mg}$ once a month produces clinical effects similar to those seen with $5 \mathrm{mg}$ daily, including mean percentage change in BMD at the lumbar spine and the hip, bone turnover markers, and 
Table I Summary of adverse events

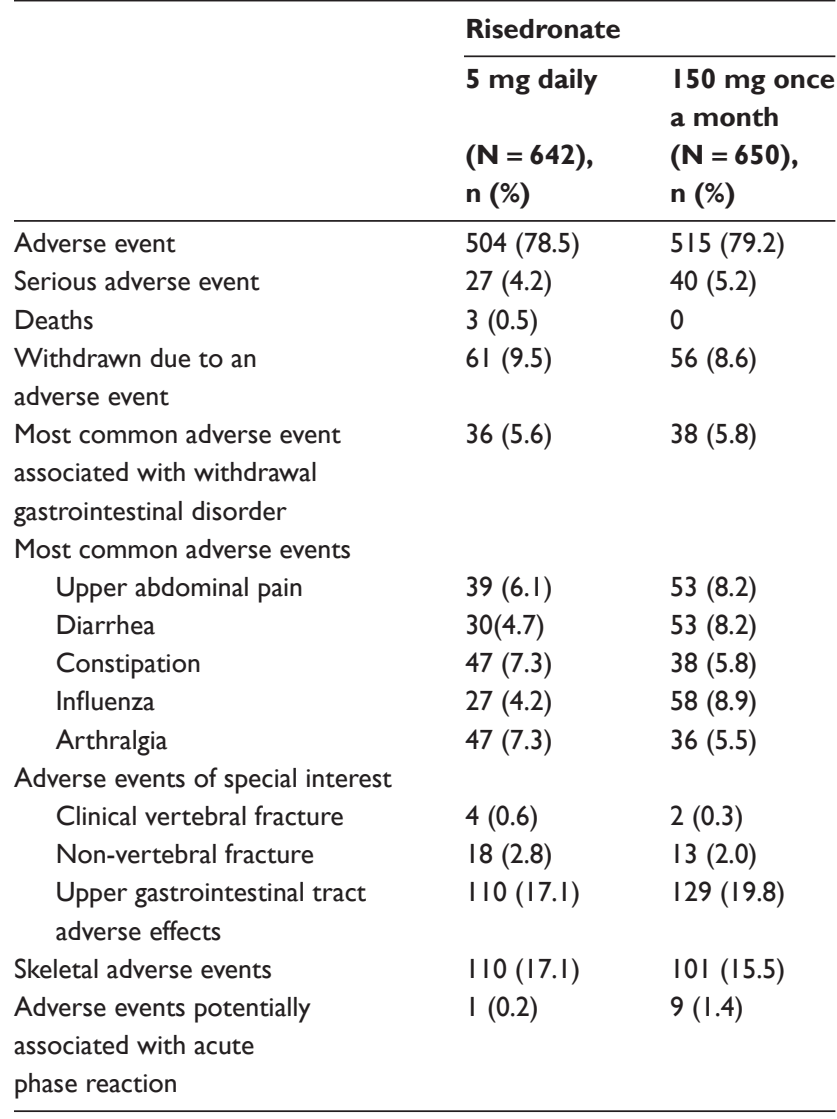

morphometric vertebral fractures. These ranges of risedronate dosing options, from daily to weekly to monthly, have the potential to improve patient adherence to therapy, and thereby optimize therapeutic outcomes.

\section{References}

Actonel label. 2007. URL: http://wwww.fda.gov/cder/foi/label/2007/ 020835s025lbl.pdf

Baroutsou B, Babiolakis D, Stamatiadou A, et al. 2004. Patient compliance and preference of alendronate once weekly administration in comparison with daily regimens for osteoporotic postmenopausal women EULAR 2004 [AbstractSAT0240].

Brown JP, Kendler DL, McClung MR et al. 2002. The efficacy and tolerability of risedronate once a week for the treatment of postmenopausal osteoporosis. Calcif Tissue Int, 71:103-111.

Caro JJ, Ishak KJ, Huybrechts KF, et al. 2004. The impact of compliance with osteoporosis therapy on fracture rates in actual practice. Osteoporos Int, 15:1003-8.

Chesnut CH, Skag A, Christiansen C, et al. 2004. Effects of Oral Ibandronate Administered Daily or Intermittently on Fracture Risk in Postmenopausal Osteoporosis. J Bone Miner Res, 19:1241-9.

Chrischilles EA, Butler CD, Davis CS, et al. 1991. A model of lifetime osteoporosis impact. Arch Intern Med, 151:2026-32.

Cramer JA, Gold DT, Silverman SL, et al. 2007 A systematic review of persistence and compliance with bisphosphonates for osteoporosis. Osteoporos Int, 18:1023-31.

Cramer JA, Amonkar M, Hebborn A, et al. 2004. Assessing the relationship between bisphosphonate dosing regimen and treatment adherence among post-menopausal osteoporotic women. Arthritis Rheum, 15:S677.
Cranney A, Tugwell P, Adachi J, et al. 2002. Osteoporosis Methodology Group and The Osteoporosis Research Advisory Group. Meta-analyses of therapies for postmenopausal osteoporosis. III. Meta-analysis of risedronate for the treatment of postmenopausal osteoporosis. Endocr Rev, 23:517-23.

Delmas PD, Recker RR, Chesnut CH III, et al. 2004. Daily and intermittent oral ibandronate normalize bone turnover and provide significant reduction in vertebral fracture risk: results from the BONE study. Osteoporos Int, 15:792-8.

Delmas PD, Benhamou CL, Man Z, et al. 2007. Monthly dosing of $75 \mathrm{mg}$ risedronate on 2 consecutive days a month: efficacy and safety results. Osteoporos Int, doi: 10.1007/s00198-007-0531-9.

Delmas PD, McClung MR, Zanchetta JR, et al. 2008. Efficacy and safety of risedronate $150 \mathrm{mg}$ once month in the treatment of postmenopausal osteoprosis. Bone, 42:36-42.

Eastell R, Garnero P, Vrijens B, et al. 2003. Influence of patient compliance with risedronate therapy on bone turnover marker and bone mineral density response: the IMPACT study. Calcif Tissue Int, 72:408 [Abstract P-297].

Emkey R. 2004. Alendronate and risedronate for the treatment of postmenopausal osteoporosis: clinical profiles of the once-weekly and once-daily dosing formulations. Med Gen Med, 6:6.

Ettinger M, Gallagher R, Amonkar M, et al. 2004. Medication persistence is improved with less frequent dosing of bisphosphonates, but remains inadequate. Arthritis Rheum, 15:S1325

Finigan J, Bainbridge PR, Eastell R. 2001. Adherence to osteoporosis therapies. Osteoporos Int, 12:S48-9 [Abstract P110].

Gold DT, Safi W, Trinh H. 2006. Patient preference and adherence: comparative US studies between two bisphosphonates, weekly risedronate and monthly ibandronate. Curr Med Res Opin, 22:2383-91.

Harris ST, Watts NB, Genant HK, et al. 1999. Effects of risedronate treatment on vertebral and nonvertebral fractures in women with postmenopausal osteoporosis: a randomized controlled trial. Vertebral Efficacy With Risedronate Therapy (VERT) Study Group. JAMA, 282:1344-52.

Harris ST, Watts NB, Li Z, et al. 2004. Two-year efficacy and tolerability of risedronate once a week for the treatment of women with postmenopausal osteoporosis. Curr Med Res Opin, 20:757-64. Erratum in: Curr Med Res Opin, 20:1690.

Keen R, Jodar E, Iolascon G, et al. 2006. European women's preference for osteoporosis treatment: influence of clinical effectiveness and dosing frequency. Curr Med Res Opin, 22:2375-81.

Kendler D, Kung AW, Fuleihan Gel-H, et al. 2004. Patients with osteoporosis prefer once weekly to once daily dosing with alendronate. Maturitas, 48:243-51.

Lekkerkerker F, Kanis JA, Alsayed N, et al. 2007. Adherence to treatment of osteoporosis: a need for study. Osteoporos Int, 18:1311-7.

Lombas C, Hakim C, Zanchetta JR. 2001. Compliance with alendronate treatment in an osteoporosis clinic. J Bone Miner Res, 15:S529 [Abstract M406].

McClung MR, Geusens P, Miller PD, et al. 2001. Effect of risedronate on the risk of hip fracture in elderly women. $N$ Engl J Med, 344:333-40.

McCLung MR, Benhamou CL, Man Z, et al. 2007. The efficacy and tolerability of a monthly dosing regimen of $75 \mathrm{mg}$ risedronate dosed on 2 consecutive days a month for the treatment of postmenopausal osteoporosis-1 year stdy results. Osteoporos Int, 18:S217-8.

McCombs JS, Thiebaud P, McLaughlin-Miley C, et al. 2004. Compliance with drug therapies for the treatment and prevention of osteoporosis. Maturitas, 48:271-87.

Mellstrom DD, Sörensen OH, Goemaere S, et al. 2004. Seven years of treatment with risedronate in women with postmenopausal osteoporosis. Calci Tissue Int, 75:462-68.

Mersfelder T, Armitstead JA, Ivey MF, et al. 1999. A medication use evaluation of alendronate: compliance with administration guidelines. Pharm Pract Manag, 18:50-8.

Miller PD, McClung MR, Macovei L et al. 2005. Monthly oral ibandronate therapy in postmenopausal osteoporosis: 1-year results from the MOBILE study. J Bone Miner Res, 20:1315-22. 
North American Menopause Society. 2006. Management of osteoporosis in postmenopausal women: 2006 position statement of the North American Menopause Society. Menopause, 13:340-67.

Recker RR, Gallagher R, Amonkar M, et al. 2004. Medication persistence is better with weekly bisphosphonates, but it remains suboptimal. J Bone Miner Res, 19(Suppl 1):S172 [Abstract SA407].

Reginster J, Minne HW, Sorensen OH, et al. 2000. Randomized trial of the effects of risedronate on vertebral fractures in women with established postmenopausal osteoporosis. Vertebral Efficacy with Risedronate Therapy (VERT) Study Group. Osteoporos Int, 11:83-91.

Reginster JY, Burlet N. 2006. Osteoporosis: a still increasing prevalence. Bone, 38(Suppl 1):S4-S9.

Sebaldt R, Shane L, Pham B, et al. 2004. Longer-term effectiveness outcomes of non-compliance and nonpersistence with daily-regimen bisphosphonate therapy in patients with osteoporosis treated in tertiary specialist care. Osteoporos Int, 15(Suppl 1):S107 [Abstract P391SA].
Segal E, Tamir A, Ish-Shalom S. 2003. Compliance of osteoporotic patients with different treatment regimens. Isr Med Assoc J, 5:859-62.

Simon JA, Lewiecki EM, Smith ME, et al. 2002. Patient preference for once-weekly alendronate $70 \mathrm{mg}$ versus once-daily alendronate 10 mg: a muticenter, randomized, openlabel, cross-over study. Clin Ther, 4:1871-86.

Weiss TW, Gold DT, Silverman SL et al. 2006. An evaluation of patient preferences for osteoporosis medication attributes: results from the PREFER-US study. Curr Med Res Opin, 22:949-60.

World Health Organization. 2003. Adherence to long-term therapies: evidence for action. http://www.who.int/chronic_conditions/en/ adherence_report.pdf.

Yood RA, Emani S, Reed JI, et al. 2003. Compliance with pharmacologic therapy for osteoporosis. Osteoporos Int, 14:965-8. 